\title{
6
}

\section{TABUS LINGUÍSTICOS DE DECORO NO GUINEENSE ${ }^{1}$}

\section{DECORUM-RELATED LINGUISTIC TABOOS IN GUINEA-BISSAU CREOLE}

\begin{abstract}
Lauci Correia ${ }^{2}$
Universidade da Integração Internacional da Lusofonia Afro-Brasileira
\end{abstract}

Manuele Bandeira ${ }^{3}$

Universidade da Integração Internacional da Lusofonia Afro-Brasileira

Shirley Freitas 4

Universidade da Integração Internacional da Lusofonia Afro-Brasileira

Resumo: Este trabalho objetiva compreender alguns aspectos linguísticos e sociais relacionados ao uso dos tabus linguísticos de decência ou decoro (ULLMANN, 1973, 1977) em guineense. Para tal, foram aplicados questionários a estudantes guineenses da Unilab, campus Malês, com perguntas relativas aos termos para se referir a conceitos sexuais e à concepção de xingamentos. Com base nas análises, nota-se que não só existem tabus linguísticos em guineense como sua relação com cada falante interfere nas escolhas dos vocábulos, podendo levar à manutenção de determinados itens (rabada "nádegas"), à diminuição no uso de outros considerados "indecorosos" (katota "vagina") ou mesmo à criação de novas palavras ou à extensão semântica de itens existentes (bunda referindo-se à "vagina").

Palavras-Chave: Guiné-Bissau; Guineense; Tabu linguístico de decoro; Sexo.

1 Esse artigo é fruto do trabalho intitulado Tabus linguísticos de cunho sexual no guineense moderno (CORREIA, 2020).

2 Endereço eletrônico: laucijoaocorreia@gmail.com.

3 Endereço eletrônico: manuelebandeira@unilab.edu.br.

4 Endereço eletrônico: shirleyfreitas@unilab.edu.br. 
Abstract: This work aims to understand some linguistic and social aspects related to the use of decency or decorum-related linguistic taboos (ULLMANN, 1973, 1977) in Guinea-Bissau Creole. For that, we applied questionnaires to Guinean students from Unilab, campus Malês, with questions regarding the terms to refer to sexual concepts and the concept of name-calling. Based on the analyses, it is noted that not only do linguistic taboos exist in Guinea-Bissau Creole, but their relationship with each speaker interferes with the choices of the words, which may lead to the maintenance of certain items (rabada "butt"), the decrease in the use of other words considered "indecorous" (katota "vagina") or even the creation of new words or the semantic extension of existing items (bunda to refer to "vagina").

Keywords: Guinea-Bissau; Guinea-Bissau Creole; Decorum-related linguistic taboo; Sex.

\section{INTRODUÇÃO}

Para definição da palavra tabu, Guérios $(1979$, p. 10) advoga que “pode ser traduzida por "sagrado-proibido" ou "proibido-sagrado". Vem a ser abstenção ou proibição de pegar, matar, comer, ver, dizer qualquer coisa sagrada ou temida". O presente estudo, portanto, buscou analisar o fenômeno do tabu linguístico de decoro ou decência (em referência a órgãos sexuais e ao ato sexual), de acordo com a classificação proposta por Ullmann $(1973,1977)$, no guineense. Desse modo, objetivamos compreender e discutir alguns aspectos linguísticos e sociais envolvidos no referido fenômeno. Como forma de obter dados em conjunto com uma fundamentação teórica, recorremos à pesquisa de campo com questionários compostos de perguntas a respeito de palavras tabuizadas no guineense. Assim, foram aplicados questionários com 50 estudantes guineenses da Universidade da Integração Internacional da Lusofonia Afro-brasileira (Unilab), campus dos Malês.

O não uso de palavras e expressões, ditas tabus, no guineense moderno foi o ponto de partida para o interesse em realizar o estudo. Trabalhos sobre a GuinéBissau ainda hoje são de número restrito, em consequência disso, registram-se poucas pesquisas linguísticas voltadas ao guineense. Assim, o fenômeno em foco, até o momento, ainda não havia sido estudado, o que aponta para a relevância 
da pesquisa que tem como objeto o guineense, em geral, e o tabu linguístico, em particular. Desse modo, com este trabalho, esperamos despertar o interesse de pesquisadores para o estudo sobre tabu linguístico, uma vez que apresenta impacto na língua, causando neologismos, formação de novas palavras, conforme aponta Almeida (2007), assim como o desaparecimento de itens considerados "indecorosos", além de fomentar a variação linguística. Para mais, esta pesquisa visa fornecer registros que auxiliem estudiosos e pesquisadores em etimologia a ter acesso a palavras em guineense que possam, porventura, no futuro se encontrar extintas. Através da discussão aqui apresentada, espera-se que este estudo sirva de alicerce para outros trabalhos sobre o fenômeno não só em guineense, mas também em outras línguas.

Para fins organizacionais, o presente estudo se dividiu em quatro seções. Na seção 1, apresentamos uma contextualização da Guiné Bissau e do guineense. A seção 2, por sua vez, tem como assunto o tabu e as consequências do seu uso para os estudos de neologismos e de etimologia. A seção 3 enfoca a metodologia adotada no estudo. Na seção 4, tem-se por objetivo apresentar análises das respostas dos dados levantados. Por fim, são apresentadas as considerações finais obtidas pelo estudo.

\section{GUINÉ-BISSAU E O GUINEENSE}

A Guiné-Bissau é um país da costa ocidental da África, com 36.125 km² de superfície total e apenas $28.800 \mathrm{~km}^{2}$ habitável, faz fronteira ao norte com o Senegal, ao leste e sudeste com a Guiné-Conacri e a oeste com Oceano Atlântico (CHAPOUTO, 2014). É constituído por 1,5 milhões de habitantes subdivididos nas seguintes etnias: balantas (30\%), fulas (20\%), manjacos $(14 \%)$, mandingas $(13 \%)$, papéis $(7 \%)$, outros grupos étnicos $(16 \%)$, contudo nem sempre as percentagens dos grupos étnicos são exatas, não se sabe ao certo qual é a etnia 
majoritária. A maior parte da sua população vive em zonas rurais (interior do país) e a principal atividade econômica do país é a agricultura (CHAPOUTO, 2014).

O território guineense abarca inúmeros grupos étnicos e há cerca de 22 línguas, dentre elas, 20 são línguas autóctones (também chamadas de línguas étnicas e faladas no cotidiano de uma determinada localidade ou comunidade, podendo não ser a língua materna daquele povo), uma possui o status de língua oficial e é a segunda língua da maioria (o português), e uma é a língua mais falada na Guiné-Bissau (a língua nacional, o guineense ou kriol) (COSTA, 2014).

Desse modo, no guineense, por ser uma língua crioula de base lexical portuguesa, a maior parte do léxico básico tem o português como fonte com traços de outras línguas étnicas, contudo é uma língua independente do português em todos os níveis estruturais, assumindo o papel de língua de comunicação entre as etnias da Guiné-Bissau, embora fosse, no passado, uma língua ignorada pelos portugueses e proibida nas instâncias públicas (COSTA, 2014). Sua importância só foi reconhecida depois da independência do país.

Consequentemente, vale relembrar que o processo histórico da GuinéBissau foi um veículo importantíssimo para formação dessa língua, ainda que esta não seja oficial como o português, é a língua mais falada e considerada língua de unidade nacional. Na seção seguinte, serão abordados os conceitos dos tabus linguísticos, como e quando ocorrem e quais são suas influências linguísticas e sociais.

\section{TABUS (LINGUÍSTICOS)}

O tabu linguístico está relacionado à proibição, às limitações das palavras consideradas "desagradáveis" e rudes, logo esses itens são adaptados para que se tornem mais "suaves" e menos constrangedores. A proibição de uso das 
palavras consideradas "chocantes" colabora para o desaparecimento das palavras, o que não facilita os estudos etimológicos, pois o tabu pode impedir os estudiosos de conhecer o étimo das palavras-tabu. Além disso, pode haver uma substituição das palavras consideradas desagradáveis por novas palavras, impulsionando o neologismo (VIARO, 2011). Por exemplo, de acordo com Viaro (2011, p. 292), no português: “[...] denominações chulas dicionarizadas, referentes ao inseto são: luzecu, abre-cu, caga-fogo e cu-de-fogo. O vocábulo caga-lume, citado por Bluteau, contudo, sobreviveu, mas por eufemismo, tornou-se vagalume". Ainda com relação aos neologismos, Guedelha (2011) aponta para o impacto do tabu na criação de novas palavras no português através de processos de prefixação, sufixação, composição, mudança fonética, metaforização, dentre outros.

Ainda que o tabu linguístico seja universal, o mesmo varia entre as comunidades, sendo um fenômeno comum existente nas sociedades e culturas. Segundo alguns ensinamentos domésticos e etiquetas sociais, se alguém não se abstiver de pronunciar palavras-tabu, estará sujeito não só às pressupostas "desgraça" e "infelicidade", mas prejudicará não só a si, como também a sua família e seu lar, para além da desaprovação social (GUÉRIOS, 1979).

É comum observar tabus sobre nomes de pessoas, religião, grau de parentesco, dos animais, nomes dos mortos, partes do corpo humano como órgãos sexuais e doenças. Com base nas pesquisas de Almeida (2007), nomes de doenças podem ser tabuizados, como o caso de tuberculose que, em muitas circunstâncias no passado, foi evitado, substituindo-se por nomes como delicada doença do peito, doença ruim, fininha, fraqueza do peito, magra, magrinha, moléstiamagra, mal de secar, seco. Assim, a carga semântica que o termo possui fez com as pessoas evitassem ou sentissem receio de expressá-lo sob o risco de “atrair a doença para si ou para o lar". 
Conforme Benke (2012), o sentimento do proibido numa pessoa pode engendrar o tabu linguístico, restringindo assim usos de alguns vocábulos e frases. Segundo a autora, o tabu, muitas vezes, é tratado como um patrimônio cultural e social, pois é um "elo" de geração em geração, compartilhando-se assim crenças, hábitos e costumes de pessoas; acredita-se, por isso, que existe desde os tempos mais remotos. É notável, por exemplo, que algumas pessoas ainda sentem receio de dizer palavras como menstruação ou pronunciar o nome, até mesmo, de doenças como tuberculose, HIV (Vírus da Imunodeficiência Humana), câncer, dentre outros, porque ainda pode ser tabu falar sobre enfermidades no meio social. Substituir, portanto, itens menos agradáveis para suavizar o impacto da palavra constrangedora ou substituir uma palavra com o efeito semântico considerado mais "suave" podem ser procedimentos utilizados diante de uma situação em que o falante se depara com um tabu linguístico ao optar por não usá-lo.

Essa suavização do vocábulo leva ao eufemismo, sendo, portanto, um recurso linguístico para tornar palavras menos ofensivas sem que se constranja o interlocutor. Guedelha (2011) aponta ainda que os eufemismos - que atuam como uma espécie de "amortecimento" de um dado vocábulo, que deixa de ser usado e é substituído por outro - variam a depender da sociedade e do período de tempo. Por exemplo, a palavra pensão, antes associada a prostíbulos, foi perdendo tal referência com o passar dos anos.

Sobre estas substituições dos termos e vocábulos, Benke (2012), baseada em Coseriu (1982), considera que o tabu linguístico provoca o acréscimo de metáforas na língua, porque é frequente ver o significado de uma palavra sendo transferido para outra ou por meio de comparação ou por ser considerada menos "bonita" ou "suave", a exemplo de linguiça que, em português brasileiro, referese literalmente a tripa recheada com toucinho e carne crua, mas metaforicamente 
pode remeter ao órgão sexual masculino, substituindo, em alguns contextos, o item pênis e equivalentes.

Guedelha (2011) também se refere ao papel das metáforas e dos hiperônimos (em relação aos tabus) na criação de novos vocábulos. Nas metáforas, são atribuídos novos usos a palavras já existentes na língua e esse novo uso é baseado na comparação entre dois conceitos tomando como base a semelhança entre eles. Nas palavras de Guedelha (2011, p. 55): “a metáfora tem sempre, no seu nascedouro, o sabor da novidade. É o "novo" que se instaura na linguagem, mas com o passar do tempo o uso repetido do termo metafórico vai se cristalizando e se estabelecendo na língua como uma nova palavra". Um exemplo de metáfora, relacionada a um tabu linguístico, é o uso da palavra poupança para se referir às nádegas. Os hiperônimos, por seu turno, referem-se ao uso de um termo mais geral para indicar um mais específico. Como exemplos, está o uso da palavra necessidades em referência ao ato de defecar e do termo membro para remeter ao pênis.

Dentre os diversos tabus linguísticos, este estudo terá como foco os chamados tabus de decoro segundo classificação proposta por Ullmann (1973, 1977). Esses tabus se referem a termos relativos a partes do corpo humano, necessidades naturais e sexo, incluindo ainda os chamados palavrões ou xingamentos. De acordo com a discussão de Guedelha (2011), os palavrões se relacionam aos tabus de decoro, na medida em que, logo após a sua criação, esses termos são tabuizados, havendo a necessidade de um eufemismo para suavizar o uso desse palavrão. A esse respeito, o autor traz a opinião de Pinker (2008), que considera o uso dos palavrões associados a tabus (como sexo e órgãos do corpo) como carregados de hipocrisia, uma vez que os palavrões são empregados por pessoas de diferentes idades e classes sociais para se referir a conceitos que são inerentes ao ser humano, dos quais não é possível prescindir. Dado o caráter cotidiano dos conceitos, os palavrões terminam se inserindo em um jogo de 
forças opostas: de um lado, está a atração, que leva a um uso recorrente dos termos; do outro, está o choque, que atua para evitar o termo (tabuizando-o) por ir de encontro ao que seria adequado.

Ainda no que diz respeito ao uso dos tabus, as diferenças entre sexos é uma realidade de quase toda a sociedade que se reflete também nos tabus linguísticos. Mulheres, por exemplo, influenciadas por limitações e proibições impostas sobre o sexo feminino, podem usar menos, ou mesmo não usar, termos considerados "inaceitáveis" para mulheres dizerem. De acordo com Mollica e Braga (2007, p. 33), isso "não impede, entretanto, que ainda possamos ouvir e utilizar expressões que "não fica[m] bem para uma garota falar"'". De acordo com Leite e Callou (2005, p. 37),

os estudos dialetológicos clássicos, por sua vez, tinham procurado mostrar que, se por um lado as mulheres tendiam a manter traços mais arcaizantes, por outro, aceitavam mais facilmente os neologismos, apresentando maior instabilidade na fala do que os homens.

Na seção a seguir, será explicitado o tipo de pesquisa feita para recolha de dados, caracterizando o questionário aplicado e os participantes do estudo.

\section{METODOLOGIA}

Para realização da pesquisa, após a leitura dos materiais que constituem o referencial teórico (discutido na seção precedente), foram elaborados questionários aplicados com alunos guineenses da Unilab, campus dos Malês. Os questionários foram constituídos de 03 (três) perguntas com respostas fechadas e 05 (cinco) com respostas abertas. As perguntas com respostas fechadas requeriam que os entrevistados indicassem os termos usados para se referir a "nádegas", "órgãos sexuais masculino e feminino" e "ato de ter relações sexuais". Já as perguntas com respostas abertas se referiam à concepção dos entrevistados 
sobre xingamentos, englobando perguntas relativas ao conceito do termo, quais os xingamentos mais usados, em que contextos é possível xingar e quando não é possível, entre outras. Com relação aos termos relativos aos "órgãos sexuais masculino e feminino", deve-se mencionar que as perguntas requeriam os termos de forma geral, não fazendo distinções mais acuradas, como entre vagina (interna e externa) e vulva, e entre pênis e testículos. É possível inclusive que o léxico do guineense não apresente todas as distinções mencionadas (como se observa no santome, uma língua crioula de base lexical portuguesa, que usa um único termo - kinhon - para se referir a pênis e testículos). Contudo, somente um estudo mais detalhado, com perguntas mais específicas, poderia responder com mais exatidão a essa questão, não se constituindo como escopo da pesquisa.

Na seção seguinte, que apresenta a análise dos dados, foi adotado o seguinte padrão: as palavras e expressões do guineense são grafadas em negrito seguidas de sua glosa em português entre aspas duplas. Ademais, as respostas dos informantes aparecem em itálico entre aspas duplas, não tendo sido feita alteração alguma na grafia das respostas. Assim sendo, é possível encontrar desvios à norma culta do português. Os casos de acréscimos, como glosas a termos guineenses, são indicados com colchetes. Após a resposta, aparece a identificação do informante, feita da seguinte forma: número do informante (por exemplo, INF1), sexo (M para masculino e F para feminino) e idade (apenas o número, por exemplo, 28). Caso a idade não tenha sido informada, virá apenas o sexo.

Após a elaboração do questionário, passou-se a sua aplicação entre os estudantes guineenses ${ }^{5}$ da Unilab. $O$ total das pessoas selecionadas para responder aos questionários foi (50) cinquenta. Inicialmente, o estudo levantou aspectos sociais dos 50 entrevistados. A primeira informação investigada diz

5 Para a coleta de dados, diante da ausência de um comitê de ética na universidade à época, solicitou-se que todos os informantes assinassem um Termo de Consentimento Livre Esclarecido. Solicitação prontamente atendida por todos os 50 entrevistados. 
respeito à idade dos informantes, posto que foi esperado que a faixa etária influenciasse uma maior ou uma menor aplicação de itens lexicais considerados tabus. Neste levantamento de dados, distribuímos os informantes em três faixas etárias gerais: (i) 20-24 anos: 22 informantes (44\% do total); (ii) 25-28 anos: 13 informantes (26\% do total); (iii) 29-32 anos: 6 informantes (12\% do total). Nove informantes não declararam sua idade, o que equivale a $18 \%$ do total. No entanto, não foram encontradas diferenças significativas no uso das palavras tabuizadas em um determinado grupo, não havendo, portanto, uma tendência maior de uso de nomes considerados "menos suaves" ou "ousados" pelos entrevistados de uma determinada faixa.

Quanto ao sexo biológico, 22 informantes são mulheres, o que corresponde a $44 \%$, e 28 entrevistados são homens, equivalendo a $56 \%$ das pessoas que responderam os questionários. O número de informantes homens foi superior ao de informantes mulheres, salientamos, contudo, que não foi uma seleção proposital, pois os questionários foram distribuídos aleatoriamente, sem atenção específica à distinção de sexo. De acordo com os dados coletados da pesquisa, os homens, por exemplo, tendem a ter limitações em dizer os nomes das partes íntimas femininas na presença das mulheres, questões dessa natureza serão abordadas mais adiante na seção 4. Acreditamos que, como a diferença é pequena entre as duas categorias, a pesquisa não foi prejudicada.

\section{$4 \quad$ ANÁLISE DE DADOS}

No questionário aplicado, a primeira pergunta de aspecto não social foi qual(is) seria(m) o(s) item(ns) lexical(is) prefererencial(is) dos entrevistados para se referir às "nádegas". As respostas variaram entre kadera, bunda e rabada "nádegas". 
Para a referência às "nádegas", quarenta entrevistados preferem rabada, seis informantes usam bunda, três utilizam ambas as palavras, rabada e bunda. Por fim, a palavra kadera só apresentou uma ocorrência de uso, isto é, apenas um informante declarou usar a forma. De acordo com os resultados, os informantes, em sua maioria, preferem usar mais o item rabada. A maior parte destas pessoas considera a palavra "menos grosseira, mais adequada, suave, menos ofensiva e mais educada" de dizer se comparada a outras expressões. Os informantes cuja preferência é o item rabada afirmam se sentir mais à vontade para referir a "nádegas" desta forma. O item bunda ocupa o segundo lugar de preferência. A maioria dos participantes admite usar esta palavra por ser "mais simples e mais fácil dizer e pronunciar". Ademais, parte dos informantes que usa rabada acha que é mais ofensivo e menos "suave" dizer bunda. O tom supostamente mais ofensivo do item bunda é comentado pela informante $20(\mathrm{~F}$, 25): “eu prefiro usar a palavra bunda, mas minha mãe sempre dizia que bunda é palavrão, então ela recomenda usar rabada". Podemos constatar, nesse breve relato, o caráter transgressor do tabu, um traço comum do fenômeno, posto que o falante, ainda que tenha sido ensinado a usar a dada palavra (rabada), opta por usar outra (bunda).

Três informantes usaram duas formas para denominar nádegas (rabada e bunda). Um deles, a informante $1(\mathrm{~F}, 24)$, aponta que: "usava muito rabada porque aprendi que se dissesse bunda é xingamento. Então, vivendo aqui no Brasil, passei a ter mais familiaridade com o termo bunda e passei a usar a palavra tranquilamente". Nesse caso, é evidente a influência brasileira na sua fala, pois bunda é um termo usado pelos brasileiros, a exemplo da famosa música intitulada "a dança da bundinha" do grupo de axé da Bahia "É o tchan". Também houve um caso em que o informante usa os dois termos, mas em situações diferentes: "normalmente uso este termo [rabada], quando falo com pessoas mais velhas ou com aqueles que tenho respeito ou quando não somos próximos... Mas 
nos outros casos, uso bunda" (INF28, M, 23). Assim, este indivíduo usa a palavra bunda para pessoas com mais intimidade e certa proximidade. $\mathrm{O}$ meio (social) condiciona em certa medida como a pessoa lida com o tabu. Assim, um falante que também prefere bunda e rabada justifica sua preferência, alegando: "uso porque é comum". Desse modo, talvez seja frequente o uso destas palavras no meio onde cresceu e no qual estava inserido, porque, de acordo com outros relatos, o emprego do item bunda não é comum nas comunidades ou famílias alocadas em Guiné-Bissau. Portanto, embora o tabu seja um fenômeno universal presente em toda sociedade, não quer dizer que o que é tabuizado numa determinada localidade também o será em outros lugares (Cf. GUÉRIOS, 1979), mesmo quando estamos lidando com falantes de uma mesma língua que se encontram deslocados do seu país natal como é o caso dos nossos informantes guineenses que agora residem no Brasil. Além disso, enquanto é comum, em Portugal, usar o termo rabo para referência às nádegas, no Brasil, o termo, embora usado, é considerado rude por ser mais utilizado com referência à anatomia animal, sendo, por isso, de uso mais restrito se comparado ao termo bunda. Nesse sentido, é provável que tal percepção brasileira possa também ter influenciado o uso do item bunda individualmente e simultaneamente com outra forma.

Dando prosseguimento à análise, no tocante à denominação para o órgão sexual feminino ("vagina"), kunu foi a expressão preferida de vinte informantes, representando quase metade do número total dos colaboradores da pesquisa. Ainda que os informantes que usam kunu considerem uma expressão não educada e vulgar, o item foi o mais escolhido entre as outras opções, inclusive o informante 50 (M, 30) justifica: "é o nome de kriol tradicional. Pampana e katota são conotações recentes". Dezoito pessoas preferem pampana, já katota conta com a preferência de três pessoas, sendo o terceiro mais citado, com quase uma concordância nas justificativas. Os três informantes consideram katota "mais 
suave, adequada, menos constrangedora, mais elegante". Para eles, é mais comum usar esse termo em qualquer lugar sem causar constrangimento ao próximo, sendo mais apropriado do que kunu. Três informantes usam duas formas simultaneamente - dois usam kunu e pampana e um usa pampana e kota -, enquanto uns acham estas palavras mais "ofensivas" e inadequadas, outros usam as duas formas de dizer, em situações e momentos diferentes. Além das respostas obtidas nas perguntas de múltipla escolha, outras palavras foram mencionadas pelos colaboradores: femiandadi "feminilidade", bunda "bunda", katchora "vagina", putunani "vagina", mindjerdadi "feminilidade, o que faz ser mulher". Mais uma vez, houve certa concordância nas respostas com relação a esses termos, seus utentes dizem recorrer a estas palavras por serem menos "agressivas" e menos "constrangedoras", mais "polidas" e "adequadas" em relação a outras formas já citadas. Algumas destas formas podem ser consideradas neologismos no guineense, posto que não são conhecidas geralmente como itens relativos ao órgão sexual feminino, logo sem registro até o momento em dicionários com esse novo significado ("vagina"), a exemplo de katchora e putunani. Esses exemplos ilustram o processo de criação de novas palavras e significados, como consequência dos tabus linguísticos, a partir de metáforas (Cf. GUEDELHA, 2011).

Um caso entre as expressões, que chamou muito a atenção por ser inédito talvez para muitos guineenses, diz respeito ao uso de bunda para se referir a toda a parte íntima feminina. O informante $25(\mathrm{M}, 27)$ disse: "tento não chamar pelo nome. Sou meio reservado com relação a essa questão. Chamo-o de forma generalizada bunda". Nesse caso, compreendeu-se, pelo seu relato, que o informante não usa itens lexicais para se referir diretamente à "vagina", preferindo a opção genérica bunda.

Passando para as preferências dos informantes para a denominação do órgão sexual masculino ("pênis"), a maioria dos informantes (dezoito) usa 
pipixu. Os colaboradores consideram pipixu "mais educado, normal e civilizado" para referência a "pênis", alegando que chamar desta forma não incomodaria os outros ao redor nem causaria constrangimentos. Algumas justificativas para pipixu chamaram mais atenção, a exemplo da informante 37 (F) que disse: "porque, como me ensinaram a chamar isso assim, até hoje chamo assim e fico com vergonha de chamar outro nome mesmo com o meu namorado", já o informante $38(\mathrm{M}, 29)$ alega que “[pipixu] é socialmente normal em crioulo guineense". A informante $20(\mathrm{~F}, 25)$ justifica a escolha desta palavra por achar que "soa bem": "escolhi essa opção, porque soa bem e, eu não sei se essa palavra faz parte de kriol ou não". Já a informante $23(\mathrm{~F}, 22)$ deixa evidente a força inibidora do tabu na escolha de um item em detrimento de outro: "porque minha consciência pesa chamando-o [pênis] doutra forma, prefiro usar esta palavra [pipixu] ou matchundadi ["masculinidade"], o que te faz ser homem".

Em segundo lugar, dezesseis informantes usam kodjon. Kodjon foi escolhido por sete informantes do sexo feminino e nove do sexo masculino, uma diferença mínima, mas que mostra certa preferência dos colaboradores homens por kodjon. O informante $34(\mathrm{M}, 23)$ chega a conjecturar a razão para a escolha de kodjon: "aprendi a chamar assim e eu acho mais conveniente para me referir ao pênis. Ao dizer pênis vem a mim o significado testículo, pipixu já é aquela forma mais moderna de chamar kodjon, por isso não gosto. O obu é usado para xingar, por exemplo bu garandi Obu ["teu pênis é grande"]". Já para o informante $25(\mathrm{M}, 27)$, ser do sexo masculino explica a opção: “como sou homem, sinto-me mais à vontade para proferir o termo kodjon. Porém, às vezes suavizoo usando pipixu". Os informantes 34 e 25 demonstram um comportamento comum de falantes em relação ao tabu linguístico que é o de considerar a forma (o tabu) escolhida como "melhor", "mais suave" ou menos constrangedora ainda que outros falantes não tenham a mesma percepção. Os demais informantes 
homens afirmam usar kodjon por ser a forma comum em guineense, logo “simples" para eles e por ser a mais partilhada no seu dia a dia.

Para as mulheres, por seu turno, quatro usam o termo por considerarem que é o nome comum em kriol (guineense), mais "ideal", utilizado no dia a dia e mais apropriado. Elas afirmam também que os demais nomes são apenas formas "inventadas" para "enfeitar". Outras três informam usar kodjon em determinadas situações a exemplo da informante 1 (F, 24): "uso kodjon quando falo com outras pessoas, já com os meus pais, pessoas mais velhas e conservadoras [uso] matchundadi para não [se] sentirem ofendidas". Percebe-se que a informante 1 usa kodjon, mas com certas limitações talvez por ser mulher e a mulher culturalmente, em geral, é pressionada a não dizer determinadas palavras sob pena de ser julgada negativamente, algo que acontece em nível mais brando com os homens. A informante $22(F, 29)$ que prefere usar o item kodjon para referência a "pênis" também aponta a inibição promovida pelas palavras tabu no dia a dia do falante de guineense: "kodjon é o nome específico em crioulo, que eu conheço, esses nomes atuais são adaptados, porque existe um tabu pelo nome, os mais velhos não chamam esse nome no meio das crianças, elas [as crianças] não podem saber". Nota-se que tal informante (22) identifica um tabu por trás das limitações. De maneira similar, a informante $44(\mathrm{~F}, 26)$ também discorre sobre a necessidade de adequar o item referente a "pênis" a depender do seu interlocutor: "depende da pessoa a que se refere. Para um indivíduo adulto, eu uso kodjon; para uma criança é pipixu; obu eu ouvi alguém usar, mas eu não [uso]".

Em terceiro lugar na preferência, está a palavra obu (11 informantes) para referência ao órgão sexual masculino. As razões para a escolha de obu são variadas, o informante $8(\mathrm{M})$ afirma: “falo $\mathbf{O b u}$, porque esse órgão está entre [2 kuku di Obus] os testículos, portanto desta forma muitas pessoas chamam assim". O informante 8 usa o nome mais no sentido figurado da palavra, 
empregando o termo obu, porque está entre "duas bolas" (os testículos), portanto seria a razão desse nome para ele. Já o informante $18(\mathrm{M})$ sustenta: “obu é mais adequado, mas kodjon é mais vulgar para os jovens". Para o último, obu é o menos ofensivo e comum para um jovem usar em vez de kodjon.

Houve também casos em que as pessoas empregam para referência ao órgão sexual masculino mais de um item como pipixu/obu (dois informantes) e kodjon/obu (um informante). Dois informantes preferem matchundadi "masculinidade" (num processo de criação por metáfora).

Para referência ao ato sexual, vinte e um informantes preferem usar o termo fasi sexo, por eles considerada a maneira mais adequada e mais "respeitosa" como aponta o informante 39 (M, 24): "achei mais apropriado". Alguns comentários dos informantes se destacaram, por exemplo, o informante 45 (M, 28) disse: “apesar de não expressar na língua guineense, prefiro usá-lo por gosto moderado da conversa", neste caso a sua preferência se deve pelo gosto de usar expressões novas na língua, porque esta expressão presente atualmente no léxico guineense possivelmente chegou por influência do português em que há a expressão similar "fazer sexo". Outro comentário em destaque se encontra na fala da informante $30(\mathrm{~F}, 22)$ que assegura: "muitas vezes ao chamar esse ato pelo nome, as pessoas ao meu redor acham que é estúpido". Como se pode notar, preocupações com juízos de valor externos ao falante podem interferir diretamente numa inibição do uso do termo por temor de ser julgado de forma pejorativa. Esse comportamento repreensivo com relação a determinados termos indica como o tabu também está enraizado no guineense. O item moka foi o segundo mais citado, usado por dezessete pessoas. Mais uma vez, as justificativas para a preferência são de natureza variada: "sempre uso a palavra moka, na verdade me sinto mais confortável em usá-la, só que as parceiras às vezes [se] sentem constrangidas" (INF27, M, 24); "porque dessas palavras, ela [moka] que é objetiva e direta" (INF11, F, 21). 
Cinco informantes usam a forma dita ku alguin, o ato de se deitar com alguém, para referência à cópula. O informante $38(\mathrm{M}, 29)$ considera, ao que parece, a dada expressão menos "constrangedora": "porque a sociedade guineense é uma sociedade marcada pelo tabu, por isso usar dita ku alguin é mais adequado". O efeito mais "brando" da expressão dita ku alguin é também apontado como razão para a escolha da informante $2(\mathrm{~F}, 23)$ com o destaque para o fator repreensivo do tabu ser mais forte junto às mulheres, algo já apontado por outras informantes: "porque se eu falasse assim [dita ku alguin] ninguém ficaria estranho comigo, porque se chamar de outra forma a sociedade me 'viria' como uma prostituta". Como se pode perceber, o efeito do tabu sobre essa informante é significativo. Três informantes preferem usar duas formas simultaneamente (moka/dita ku alguin, fasi amor/dita ku alguin), outros três informantes individualmente usam as expressões fasi amor, fasi macardesa, relason sexual. Por fim, houve um informante que preferiu não especificar a expressão utilizada.

Passando para as perguntas não polares, o primeiro comando foi: escreva as palavras que acha que é xingamento, podendo ser as já mencionadas no questionário elou qualquer outra que conhecer. Por que as considera xingamento? A informante 30 (F, 22) cita os seguintes termos: moka "transar", kodjon "pênis", kadera "nádegas", kunu "vagina" e, em seguida, afirma "são mais usadas para xingamentos". Essa resposta foi a mais comum comparada às respostas que virão adiante, mas destacamos o fato de a informante citar kunu como palavra usada para xingar que antes foi escolhida como a palavra para denominar o órgão sexual feminino. Em seguida, a informante 30 divaga: "é o certo a dizer e comum [com referência a kunu]". Tal afirmação merece atenção, pois se kunu é comum e o "certo" a dizer conforme alegado, não seria esperado o mesmo item ser citado como xingamento.

A informante 29 (F) pondera sobre a definição categórica do que seria xingamento: "tanto esses dos questionários como outros para serem 
considerados xingamentos, vai depender da palavra que antecede ou o contexto ou momento em que são usados". Diferentemente da maioria das respostas, para esta informante, os itens só são xingamentos dependendo das palavras que as acompanham no momento em que são proferidas. Estas colocações reforçam a ideia de que as palavras isoladas não são, em geral, xingamentos para seus falantes, mas podem ser assim consideradas consoante o contexto em que tais palavras estão inseridas, a circunstância de fala e o interlocutor: "kadera, bunda ["nádegas"] são termos tidos como xingamento até um certo ponto dependendo do nível de relacionamento entre um menino e uma menina. Se for numa conversa normal com minha namorada, posso usar termo kadera e bunda, agora, se for por meio de uma discussão, o uso do termo perde o valor carinhoso e passa a ser um insulto. Portanto, o uso desses termos depende de momento e com quem estou a falar" (INF50, M, 30).

A informante $12(\mathrm{~F}, 24)$, por seu turno, considera xingamento palavras como "estúpida, atrevida, bandida, puta, ma edukada e bura", justificando “para mim são palavras fortes que não deveriam ser usadas [...] são palavras que não me "identifica" como pessoa". O interessante é que essa colaboradora não citou partes do corpo como alguns, considerando como xingamentos outros adjetivos usados para caracterizar pessoas. Já o informante $19(\mathrm{M}, 28)$ cita como xingamento "miti pé na rabo [meter pé na bunda]" e comenta "mexe com o psicológico do indivíduo [...] sendo agressivo". A expressão que, para esse informante, é xingamento, de fato é mais usada em situações tensas em guineense.

As duas últimas respostas são aquelas que consideramos ter sofrido alguma influência do meio acadêmico (Unilab) e da convivência com estudantes de outras nacionalidades como a brasileira. O informante 9 (M) considera xingamento "filho da puta, idiota, analfabeto funcional, filho de uma égua, veado, sapatona", todas expressões pertencentes ao vocabulário do português do 
Brasil, o que talvez seja produto da convivência entre guineenses e brasileiros. Por fim, em geral, moka ["transar"], moka mame ["se deitar com a mãe de alguém"], fidju di puta ["filho/a da puta"], puta ["puta"], kodjon ["pênis"], karika ["parte interna de vagina" ou "vagina"], ratchau kadera ["rachar a bunda de alguém"], fedi kodjon ["pênis fedido"], fedi kunu ["vagina fedida"] foram as palavras e expressões mais usadas como xingamentos pela maioria dos participantes da pesquisa.

A pergunta seguinte do questionário foi: que xingamento você mais usa em kriol? Como respostas, destacamos a informante $1(\mathrm{~F}, 24)$ que alega não xingar porque não gosta de ser xingada: "não gosto de xingar as pessoas porque não gosto de ser xingada. Porém, com as amigas, algumas, nesse caso, uso 'bandida', 'merda', mas, numa circunstância séria, não uso'. Esta informante afirma usar itens como bandida e merda em momentos mais íntimos com pessoas próximas, portanto, para a informante, tais palavras são tabuizadas, posto que não são usadas em qualquer circunstância, mas proibidas em momentos formais ("sérios").

O informante $28(\mathrm{M}, 28)$ também alega não proferir com frequência xingamentos: "quase não uso xingamento em kriol, porque "esse privilégio" são guardados para certas pessoas, principalmente os mais velhos, ou seja, foi sempre vetado para mim". Estas limitações de uso de alguns termos, considerados "pesados" e "feios" para os mais novos, são muito presentes na sociedade guineense. Por essa razão, de acordo com os relatos, observa-se certo estranhamento quando uma pessoa, alheia a essas limitações sociais, usa alguns termos que os outros não se sentem à vontade de falar. Esse indivíduo "infrator" é, portanto, avaliado negativamente em geral e considerado "mal-educado".

Há também expressões que, de tanto usadas, e, mesmo sendo compreendidas, em geral, como xingamento, já se tornaram "normais" ou ofendem menos como o item pora "porra" que, segundo o informante $21(\mathrm{M}, 22)$ : 
"é "usada" com muita frequência nas nossas falas [...] muitos aceitam esse palavra como normal, ignorando que é um xingamento". De maneira similar, a informante $12(\mathrm{~F}, 24)$ acha que o termo é menos ofensivo: "pora, acho uma palavra mais leve e simples que pode magoar menos uma pessoa". A maior parte dos informantes, para esta questão, apresentou respostas semelhantes, como: fidjida merda ["filho/a de merda"], bardamerda ["vai à merda"], merda ["merda"], findi rabu ["criar fenda na bunda"], findi kadera ["criar fenda na bunda"], fidjida bala ["filho/a de bala"], puta ["puta"] e fedi kadera ["bunda fedida"].

Com relação à questão subsequente (que xingamento você nunca usa e por $q u \hat{e} ?)$, nove informantes afirmam ter usado todas as expressões do seu conhecimento em guineense. Analisaremos oito respostas que mais se destacaram para além das trinta e três respostas comuns e semelhantes (a saber: kadera ["bunda"], puta ["puta"], moka ["transar"], kunu ["vagina"], tchiron ["clitóris"], puta ku padiu ["puta que pariu"], na findiu kadera ["criar fenda na bunda"], kunu di bu mame ["vagina de tua mãe"], blufu ["incircunciso"], fedi karika ["parte interna de vagina fedida"]). Esses informantes defendem o não emprego desses itens alegando serem palavras desagradáveis que não devem ser usadas no meio social, porque suas formações familiares não lhes permitem usálas.

As respostas que despertaram mais atenção foram as seguintes: "pela minha educação, não consigo usar xingamento, às vezes prefiro brigar de que xingar" (INF38, M, 29) e "não uso kunu di bu mame ["vagina da tua mãe"]. porque respeito a minha mãe e todas as mães" (INF31, F, 22). No caso do informante 38, o mesmo alega não conseguir xingar devido à educação que teve, então em resposta a essa limitação, revela preferir o confronto físico. Já a informante 31 afirma não usar "kunu di bu mamé" por respeito a sua mãe e a todas as mães. Em consonância com as razões do informante 38, o informante 10 
(M, 23) nunca profere a expressão moka mame "se deitar com a mãe de alguém" alegando que: “é muito feio. Mamé i grandi não pode ser xingada de qualquer maneira, pois é quem te deu vida, mesmo sendo mãe de outra pessoa, também poderia ser a sua". Mamé i grandi, no sentido literal da palavra, significa "mãe é grande", que seria "mãe é sagrada". De maneira semelhante, o informante 35 (M) também prefere não usar "moka mamé, não gosto de usar porque tenho respeito pela minha mãe, e não gosto que alguém a use contra mim, por isso não uso". Esse falante acredita que quem usa esta expressão para ofender outra pessoa é porque não respeita a própria progenitora. Assim, quando algo ou alguém é considerado sagrado, o respeito a este ser é imperativo para muitos indivíduos, portanto a ideia do sagrado inerente à figura materna segue em linhas gerais essa perspectiva. A mãe, portanto, para esses informantes, não deve ser ofendida. O informante $39(\mathrm{M}, 24)$ chama atenção para um aspecto comum nas palavras tabu: "moka mame ["se deitar com a mãe de alguém"], puta ki padiu ["puta que pariu"], karika de mame ["útero, vagina ou parte interna do sexo da mãe"]. Xingamentos sempre recaem em cima das mães, são palavras inapropriadas, são ofensivas". Esse falante trouxe um aspecto pertinente ao afirmar que os xingamentos em geral estão relacionados às mães, contudo o tabu em guineense não tem apenas as mães como alvo, em específico, mas as mulheres em geral. Uma prova disso foi a regularidade com que os xingamentos estavam repetidamente direcionados ao órgão sexual feminino nas respostas do questionário.

Já a informante $20(\mathrm{~F}, 25)$ cita a figura da mãe como guia para o não uso de determinados itens: "não uso blufu, porque minha mãe disse que isso deixa o sexo oposto descontrolado, o que o torna violento". Blufu se refere a aquele que não é circuncidado, assim supostamente, para aqueles que passaram pela circuncisão, é uma ofensa a sua honra chamá-los de tal maneira. 
Para o informante 41 (M, 27), "xingamento que quase nunca uso é moka, porque perdi o costume desde criança. Na infância sempre que usava a expressão era repreendido". Nota-se nessa fala que repreensões sociais, mesmo em tenra infância, podem fazer com que o falante não crie o hábito de proferir determinadas palavras. A ação proibitiva envolta ao tabu também pode ser observada na fala do informante $28(\mathrm{M}, 23)$ : “xironeta não usei nunca por não ter esse privilégio até o momento e o contexto onde vivo não permite o emprego dessa palavra". O item xironeta, traduzido como "clitóris", é uma palavra recentemente criada a partir da palavra tchiron ["clitóris"].

A questão posterior no questionário foi: na sua opinião, quem xinga mais em kriol a mulher ou homem e por que você acha isso? As respostas indicaram quatro abstenções, sete informantes afirmaram não haver diferença entre as categorias mencionadas, como apontado pelo informante 25 (M, 27): “como sou homem e convivo mais com meus companheiros homens, acabo escutando mais deles, mas ambos [os sexos] xingam". Tal afirmação foi corroborada por outros informantes, como: "há um número considerável de xingamentos por ambas as partes, mas isso não atribui a nenhuma parte uma maior percentagem nesta prática" (INF36, M, 26); o informante $4(\mathrm{M})$ demonstrou não ter uma opinião absoluta quanto à questão: "não tenho opinião quem xinga mais, acho que xingar é uma questão social e psicológica, portanto não sei dizer quem xinga entre homens e mulheres". Ademais, dezesseis pessoas apontam as mulheres como as que mais xingam, dentre as dezesseis, dez informantes são mulheres e, por fim, vinte e dois informantes afirmam ser os homens que mais xingam, dentre os vinte e dois, doze entrevistados são mulheres.

Quanto às respostas que atribuem às mulheres o hábito de xingar mais, alguns relatos se destacaram, como o do informante $41(\mathrm{M}, 27)$ que explica a razão de as mulheres liderarem o uso do tabu: "as mulheres porque são as mais impetuosas, tanto que em situações de raiva, xingam com facilidade". De modo 
semelhante, a informante 40 (F, 22) explica: "a mulher, porque ela dificilmente entra em confronto físico, mas sim verbal". De acordo com estas duas afirmações, as mulheres, supostamente por falta de força física e/ou pelo hábito do não confronto corpo a corpo, recorrem, por isso, aos ataques verbais, xingando mais em relação aos homens. Outros informantes acreditam que as mulheres xingam mais não por razões de ordem física, mas por falarem muito, ampliando-se assim as oportunidades para os xingamentos como apontam os informantes $15(\mathrm{M})$ ("na minha opinião, as mulheres xingam mais em kriol, porque as mulheres falam muito") e 30 (F, 22) ("acho que são as mulheres porque falam mais então há tendência de xingar"'). Para esses informantes, falar mais leva a xingar mais. Outra informante (INF29, F) acredita que as mulheres falam mais itens tabuizados, mas salienta uma característica relacionada aos itens usados pelos homens: “acredito que a mulher xinga mais, porém o xingamento do homem é o pior, é mais pesado". Em contrapartida, para os informantes que defendem os homens como aqueles que mais xingam, as razões podem começar pela falta de convivência com o sexo oposto (INF16, M, 28 - "eu acho os homens, talvez seja porque passo mais tempo com os homens do que as mulheres"), passando por uma tradição notadamente sexista e generalizante (INF23, F, 22 - "homem xinga mais, porque é "normal", a mulher não deve xingar. Os xingamentos que conheço são mais na direção "de homem para mulher"/ INF14, F - "pra mim, acho que são os homens, porque eles gostam de usar as palavras que machucam").

De forma geral, não foi possível observar grandes diferenças entre mulheres e homens no quesito "quem xinga mais", contudo nota-se que a maior parte das palavras e expressões compreendidas como xingamentos tem como alvo alegorias relacionadas ao sexo feminino. Assim, tanto homens como mulheres usam expressões tabuizadas com referência à mulher. Em contrapartida, duas informantes fugiram parcialmente à regra, mencionando 
também palavras que utilizam como xingamento, voltadas ao sexo masculino: "moka mame ["se deitar com a mãe de alguém"], bu kadera ["tua bunda"], bu fedi kunu sin ["tua vagina fedida"], bu kumpridu kodjon ["teu pênis longo"]" (INF5, F, 22). Um exemplo de resposta semelhante foi a informante 47 (F, 20): “o xingamento que eu mais uso em kriol são: kunu du mamé [“vagina da tua mãe”], fidju di puta ["filho/a de puta"], gintiu ["gentio"], kodjon du papé ["pênis do teu pai"]". Outras formas de xingar analisadas nas respostas ocorrem por atribuição de características animais ao ser humano, como exemplo, temos a informante 20 (F, 25): “kabesa kuma bagri ratchadu na metadi ["cabeça igual de bagre aberta no meio"]".

Dando prosseguimento à análise, na última questão, buscamos compreender em que situações a pessoa é impulsionada ou desencorajada a xingar (em que situações de conversa, você acha que uma pessoa pode xingar? E em que situações seria inadequado? Por quê?). Como se pode observar também em algumas perguntas anteriores, as questões relativas aos xingamentos ilustram a tensão existente entre a atração e o choque quanto ao seu uso conforme discutido na seção 2.

Desse modo, oito pessoas acharam que o xingamento pode acontecer no momento de conflitos ou brincadeiras com pessoas muito próximas ou íntimas (INF41, M, 27 - “em situações de irritação ou de convivência com pessoas íntimas... Porque uma pessoa irritada, muitas vezes, perde controle de si mesmo, aí pode falar qualquer coisa" / INF29, F - "pode acontecer nas brincadeiras quando os envolvidos têm uma certa amizade ou no momento de briga mesmo"). Um total de vinte e três pessoas responderam que os xingamentos geralmente aparecem, em situações de tensões, de discórdias, brigas, exaltações dos ânimos e raiva, como, por exemplo, nos momentos de acompanhar jogos de futebol e circunstâncias similares em que se proferem xingamentos como forma de manifestar a disposição perante aquela situação, não sendo direcionado a outras 
pessoas presentes. Nesse sentido, o informante $10(\mathrm{M}, 23)$ usa fidjida puta "filho/a de puta", mas salienta que usa "não para xingar outra pessoa, falo sempre quando assisto filme, jogo". Contudo houve casos em que o falante usa certas palavras para causar algum efeito no seu interlocutor, isto é, profere determinadas expressões com o intuito de ofender o seu ouvinte, como, por exemplo, a situação do informante 3 (M, 32) que explica: "uso kadera, principalmente quando me encontro irritado, a minha tendência é proferir a seguinte frase: na findiu kadera ["criar fenda na bunda"]".

Encontramos também informantes que acham que, em momento algum, devem ser proferidos xingamentos, pois não são apropriados ou adequados para uso, como a informante $1(\mathrm{~F}, 24)$ ("em nenhuma situação, pois acho desnecessário proferir uma palavra que causa constrangimento ou que diminua alguém”), o informante 39 (M, 24) ("não consigo encontrar situações, porque são inapropriados em "qualquer circunstâncias"”), o informante 41 (M, 27) ("para mim, nenhuma situação é adequada para xingar. Porque para mim não é bom que alguém xingue outrem ou mesmo quando [o xingamento] não é direcionado a ninguém”) e a informante $31(\mathrm{~F}, 22)$ ("em nenhum momento porque o que é normal para mim pode ser ofensivo para outro"). Por outro lado, houve quem achasse que xingamento não precisa ter um momento para uso, podendo ser utilizado regularmente (INF36, M, 26 - “em qualquer que seja a situação da conversa, a pessoa pode xingar, porque não há momento exato").

Para outros informantes, a questão não é a palavra em si como defende o informante $41(\mathrm{M}, 27)$ : "para mim xingamento, tem mais a ver com a forma como a pessoa fala, tom de voz". Segundo esse informante, xingamentos não são apenas palavras ou expressões consideradas rudes, mas a forma como falar, a intensidade de voz, tudo isso pode não ser "suave" e talvez cause constrangimentos. 
Outras pessoas defendem que não sejam proferidos xingamentos em determinadas circunstâncias como em igrejas, debates, reuniões (INF50, M, 30 “numa situação normal. Por exemplo, não posso xingar alguém num ambiente normal, se for num momento informal, tipo briga aí sim" / INF10, M, 23 - "não seria adequado xingar em um pedido de conselho, numa participação na aula, reza ou numa conversa séria"). Por fim, houve respostas que indicam que os xingamentos não devem ser empregados diante de crianças para que elas não aprendam palavras "inadequadas", na frente de idosos e de pessoas com as quais não se tem intimidade (INF8, M - “em situações familiares, em contextos formais, e quando estamos junto com menores. Porque influencia as crianças negativamente" / INF23, F, 22 - "quando estamos com alguém que não temos intimidade ou pessoas mais velhas (conservadoras), porque não xingar nestes momentos evita o constrangimento").

Após uma interpretação dos dados, adiante serão apresentadas as considerações finais do trabalho.

\section{CONSIDERAÇÕES FINAIS}

O objetivo precípuo do estudo foi compreender alguns traços linguísticos e sociais por trás dos tabus em guineense. Assim, a partir da análise do corpus, constatou-se que o fenômeno do tabu linguístico tem impacto na escolha ou na rejeição dos informantes com relação aos itens lexicais com referência a sexo (tais como órgãos sexuais masculino e feminino, por exemplo). Através dos dados analisados da pesquisa, observamos que os tabus linguísticos condicionam os informantes à diminuição do uso de alguns vocábulos como também levam ao emprego de novos itens e/ou à extensão semântica das palavras já existentes na língua (Cf. GUEDELHA, 2011; VIARO, 2011). 
Com relação aos itens para se referir a "nádegas", "órgãos sexuais masculino e feminino" e "ato sexual", observou-se que os participantes, por vezes, evitam uma dada palavra por considerá-la inadequada (um tabu) e recorrem a um outro vocábulo, o que evidencia o processo do eufemismo e o potencial neológico associado aos tabus. Ademais, notou-se também que a identificação de um item como tabu variou entre os informantes, demonstrando que, mesmo dentro de um mesmo grupo, essa interpretação é diversa.

De maneira geral, os relatos dos informantes repetidamente indicaram a importância dos elementos envolvidos em uma situação de fala para o uso do tabu. Assim, para os entrevistados, majoritariamente, há uma tese de que palavras isoladas não são, em geral, xingamentos, contudo passam a ser percebidas desse modo conforme o contexto em que tais palavras estão inseridas, a circunstância de fala (formal ou informal) e o interlocutor (íntimo ou não íntimo). Portanto, na análise do corpus, ao que parece as circunstâncias informais e interlocutor próximo ou íntimo tendem a favorecer o uso do tabu, ao passo que circunstâncias formais e a identidade desconhecida ou não íntima do interlocutor parecem inibir o emprego do tabu.

Outro fato de destaque é que, embora tenhamos encontrado nos relatos de alguns informantes uma rejeição quase absoluta (no discurso) com relação ao uso de itens ditos "xingamentos", esses informantes, supostamente mais refratários aos tabus, fazem o emprego das palavras tabuizadas. Esse resultado nos aponta que há usualmente um abismo entre o que o informante revela pensar ser o mais "correto" (não usar termos ditos xingamentos) e o que de fato acontece nos seus registros de fala no que diz respeito ao tabu.

Embora não tenha sido possível observar uma distinção definida entre homens e mulheres, pois ambos demonstraram fazer uso de termos tabuizados de maneira similar, notamos que as palavras e expressões compreendidas como "xingamentos", em sua maioria, possuíram como alvo representações 
relacionadas ao sexo feminino. Importante salientar que tal uso não esteve circunscrito aos homens, uma vez que ambos os sexos usaram expressões com referência à mulher.

Considerando que, neste estudo, o tabu em guineense foi, pela primeira vez, foco de uma pesquisa de natureza linguística, esperamos que o trabalho, embora incipiente diante da complexidade do fenômeno e do corpus de pequena escala numérica, possa ensejar outras pesquisas sobre a temática.

\section{REFERÊNCIAS}

ALMEIDA, Laura de. À guisa de uma tipologia para os tabus lingüísticos - proposta para um glossário. 2007. 372f. Tese (Doutorado em Linguística) Faculdade de Filosofia, Letras e Ciências Humanas, Universidade de São Paulo, São Paulo.

BENKE, Vanessa Cristina Martins. Tabus Linguísticos nas Capitais do Brasil: um estudo baseado em dados geossociolinguísticos. 2012. 314f. Dissertação (Mestrado em Estudos de Linguagens) Centro de Ciências Humanas e Sociais, Departamento de Letras, Universidade Federal de Mato Grosso do Sul, Campo Grande.

CHAPOUTO, Sandra Maria da Costa. Contributo para a descrição de aspetos fonológicos e prosódicos do crioulo guineense. 2014. 152f. Dissertação (Mestrado em Linguística) Faculdade de Letras, Universidade de Coimbra, Coimbra.

CORREIA, Lauci. Tabus linguísticos de cunho sexual no guineense moderno. 2020. 60f. Trabalho de Conclusão de Curso (Licenciatura em Letras - Português) Instituto de Humanidades e Letras, Universidade da Integração Internacional da Lusofonia AfroBrasileira, São Francisco do Conde.

COSERIU, Eugenio. O homem e a sua linguagem. Estudos da teoria e metodologia linguística. Rio de Janeiro: Presença, 1982.

COSTA, Paula Mendes. Descrição fonológica do crioulo guineense. 2014. 242f. Dissertação (Mestrado em Linguística) Centro de Artes e Comunicação, Universidade Federal de Pernambuco, Recife.

GUEDELHA, Carlos Antônio Magalhães. Tabus linguísticos como motivação na formação de palavras do PB. Working papers em linguística. Florianópolis, v. 12, n. 2, p. 4968, jul-dez 2011.

GUÉRIOS, Rosário Farani Mansur. Tabus Linguísticos. Universidade da Virgínia: Companhia Editora Nacional, 1979.

LEITE, Yonne; CALLOU, Dinah. Como falam os brasileiros. Rio de Janeiro: Jorge Zahar, 2005. 
MOLLICA, Maria Cecilia; BRAGA, Maria Luiza. Introdução à sociolinguística: o tratamento da variação. São Paulo: Contexto, 2007.

PINKER, Steven. Do que é feito o pensamento: a língua como janela para a natureza humana. São Paulo: Companhia das Letras, 2008.

ULLMANN, Stephen. Semântica: uma introdução à ciência do significado. Lisboa: Editora Fundação Calouste Gulbenkian, 1977.

ULLMANN, Stephen. Lenguaje y estilo. Madrid: Aguilar, 1973.

VIARO, Mário Eduardo. Etimologia. São Paulo: Contexto, 2011.

Nota do editor:

Artigo submetido para avaliação em: 05 de setembro de 2020.

Aprovado em sistema duplo cego em: 15 de fevereiro de 2021. 